\title{
Effects of Short-term Low- to Moderate- Dose Glucocorticoids on Immuno-inflammatory Indicators and Prognosis of Patients With Regular and Severe COVID-19: A Retrospective Cohort Study
}

\section{Jing Zhang}

Henan Provincial People's Hospital, People's Hospital of Zhengzhou University

Yi Kang

Henan Provincial People's Hospital, People's Hospital of Zhengzhou University

Hai-Bo Wang

Henan Provincial People's Hospital, People's Hospital of Zhengzhou University

Hai-Yang Liu

Henan Provincial People's Hospital, People's Hospital of Zhengzhou University

Ya-Nan Qi

Henan Provincial People's Hospital, People's Hospital of Zhengzhou University

\section{Xia Tang}

Henan Provincial People's Hospital, People's Hospital of Zhengzhou University

\section{Xiao-Ju Zhang}

Henan Provincial People's Hospital, People's Hospital of Zhengzhou University

\section{Yong Qi ( $\nabla$ srmyy123@163.com )}

Department of Respiratory and Critical Care Medicine, Henan Provincial People's Hospital, People's Hospital of Zhengzhou University, Zhengzhou, 450003

\section{Research}

Keywords: COVID-19, glucocorticoids, prognosis, CRP levels, Interleukin-6

Posted Date: November 24th, 2020

DOI: https://doi.org/10.21203/rs.3.rs-112087/v1

License: (c) (1) This work is licensed under a Creative Commons Attribution 4.0 International License. Read Full License 


\section{Abstract}

Background: To explore the effects of short-term low- to moderate- dose glucocorticoids on the immuneinflammatory indicators and 28-d prognoses of patients with regular or severe coronavirus disease 2019 (COVID-19).

Methods: The clinical data and laboratorial examination results of 66 patients with regular or severe type of COVID-19 that treated in Henan Provincial People's Hospital and Nanyang Central Hospital between January 20 and February 14, 2020 were retrospectively analyzed. Here, 36 patients that had been treated with glucocorticoids were categorized in the glucocorticoids group (GC group), while the other 30 patients that had not been treated with glucocorticoids were categorized in the control group.

Results: The immune-inflammatory indicators and prognoses of the patients in the two groups were compared. The sex, age, clinical types, and complications were not significantly different between the two groups (all $P>0.05$ ). After hospitalization, $33.3 \%$ and $6.7 \%$ of the patients in the GC group and control group were with chest distress, respectively, and the difference was statistically significant $(P=0.019)$. The duration of fever was also significantly different between the two groups (6.91 \pm 4.41 vs. $9.21 \pm 4.46$ days, $P=0.036)$, but the blood examination results within $24 \mathrm{~h}$ after hospitalization were not significantly different between the two groups (all $P>0.05$ ). The C-reactive protein (CRP) and Interleukin-6 (IL-6) levels were lower in the GC group than control group on day $7(P=0.012, P=0.035)$ but were not significantly different between the two groups on day 14 . The CRP and IL-6 levels were significantly reduced after glucocorticoids treatment on day 3, 5 and 7 (all $P<0.05$ ) in GC group. The median time of hospital stay, and 28-d prognoses were not significantly different between the two groups ( $P=0.080, P>0.999)$.

Conclusions: Glucocorticoids could decrease the levels of inflammatory indicators, but did not significantly influence other immune-related indicators and 28-d prognoses.

\section{Background}

COVID-19 is caused by SARS-CoV-2, a newly identified coronavirus similar to severe acute respiratory syndrome (SARS)-CoV [1] and World Health Organization (WHO) declared COVID-19 global situation as a pandemic on March 11, 2020. COVID-19 clinical symptoms ranged from subclinical infection, self-limiting respiratory tract illness leading to severe progressive pneumonia, multiorgan failure, and death due to massive alveolar damage and progressive respiratory failure [2]. COVID-19 is believed to be originated from wild animals followed by human-to-human transmission [3,4]. As of August 25, 2020, over 23 million patients were confirmed positive to COVID-19, and 16.3 million had recovered from infection. Coronavirus infection affect older males with comorbidities, leading to severe and even fatal respiratory diseases, such as acute respiratory distress syndrome [2,4]. A large part of deaths among males is caused by gender behavior (lifestyle), i.e., smoking and drinking behavior in men is much higher than women [1]. Currently, the treatment of COVID-19 patients consists antiviral, Chinese Traditional medicine and supportive therapy, including fluid management, oxygen therapy, and mechanical ventilation [5]. 
Corticosteroids have widely used for treating patients with SARS and MERS [6,7]. Though they did not improve outcomes during the SARS and MERS outbreaks, but delayed viral clearance and increased rates of secondary infections $[7,8]$. Currently, there was wider use of oral glucocorticoids (GC) on COVID-19 patients with immune mediated inflammatory disease who were hospitalized [9]. At the same time, there is no general evidence that COVID-19 patients benefit from GC [10]. Recently, a retrospective analysis of COVID-19 patients receiving methylprednisolone showed no beneficial clinical outcome [11]. Now, GC treatment of severe SARS-CoV-2 infection is recommended only in the context of clinical trials [12].

As no evidence-based treatment on the timing, dose, and duration of glucocorticoids administration is available, it is challenging to recommend using glucocorticoids in the treatment regime for COVID-19 [13]. In this study, the effects of low- to moderate- dose of glucocorticoids on immune-inflammatory indicators and 28-d prognoses of patients with regular or severe COVID-19 were retrospectively investigated, and provided evidence for clinical application of glucocorticoids.

\section{Methods}

\section{Patients and Study Design}

The clinical data of the patients with regular or severe type of COVID-19 who were treated in the department of infectious disease of Henan Provincial People's Hospital and the department of infectious disease of Nanyang Central Hospital between January 20, 2020 and February 14, 2020 were taken up for the study. Patients (66 cases) diagnosed with regular or severe COVID-19 based on the medical history and laboratory examination results were included in the study. The exclusion criteria were as follows: 1) patients with active pulmonary tuberculosis, idiopathic pulmonary fibrosis, bronchial asthma, bronchiectasis, pulmonary embolism, chronic respiratory failure, or other severe respiratory diseases; 2 ) accompanied with severe cardio-vascular or cerebral diseases such as malignant arrhythmia, unstable angina pectoris, acute myocardial infarction, cardiac functions $\geq$ grade 3 , stroke, and cerebral hemorrhage; 3) accompanied with severe liver or renal diseases, such as liver cirrhosis, portal hypertension, varicosity hemorrhage, acute kidney injury and chronic kidney disease; 4) in the immunosuppressive state before inclusion, such as within 1 month after radio-chemotherapy or operation, or HIV infection; 5) accompanied with dyspnea induced by neuromuscular diseases; 6) confirmed with secondary bacterial or fungal infection before inclusion; 7) pregnant or breast-feeding women; 8) accompanied with severe cognitive or psychological disorders; 9) severe lymphocyte deficiency before inclusion (absolute lymphocyte count $<300 \mu \mathrm{l}$ in peripheral blood). The diagnosis and classification of COVID-19 were performed based on the Guidelines for the Diagnosis and Treatment of COVID-19 (6th trial edition) that issued by the National Health Commission of China.

The study was approved by the ethics committee of Henan Provincial People's Hospital. Informed consents were waived in this retrospective study.

\section{Clinical data collection}


Clinical data, laboratorial examination results, imaging examination findings, treatments, and prognostic data were collected from the patients' database in the hospital. The duration of symptoms, such as chest distress duration, was defined as the time from hospitalization to the time when chest distress disappeared. Laboratorial examinations included blood routine examinations within $24 \mathrm{~h}$ after hospitalization, C-reactive protein (CRP), biochemical examinations, coagulation functions, lymphocyte subsets, and cytokine examinations. Imaging examinations included chest $\mathrm{X}$-ray and CT scanning.

\section{Treatment}

Patients who received methylprednisolone treatment were categorized into the glucocorticoids group (GC group), and the other 30 patients were categorized in the control group. Lopinavir (2 tablets, Q12H) was used for the anti-viral therapy. Patients in the GC group received intravenous injection of methylprednisolone (40-80 mg/d) according to the body weights, and the dose was decreased as per the disease conditions. The duration of glucocorticoids treatment was 3-7 d. Glucocorticoids treatment was started 6 (range 4-7) days after the appearing of clinical symptoms and 3 days (range 1-5) after hospitalization.

\section{Statistical analysis}

SPSS26.0 software (IBM Corp., Armonk, NY, USA) was used for the statistical analysis. Quantitative data in normal distribution were described with means and standard divisions, and compared with t-test. Mann-Whitney test was used for the non-parametric analysis of continuous data between two groups. Categorical data were described in percentages and compared with chi-square test or Fisher exact test. $p$ $<0.05$ was considered statistically significant.

\section{Results}

\section{Patients' characteristics}

Clinical data of 66 hospitalized patients with regular (16 patients) or severe COVID-19 (50 patients) conditions, were collected and examined. Among these patients, there were 28 males and 38 females, the age of the patients ranged from 16 to 90 years old, with the median age of 50 years old. Thirty-six patients who received methylprednisolone treatment were categorized into the glucocorticoids group (GC group), along with the other 30 patients in the control group. Twenty patients were with imaging progression before being treated with glucocorticoids, while 16 patients did not have re-examination before glucocorticoids treatment, so they were not assessed in comparisons of inflammatory and immune indicators before and after treatment.

The age, sex, clinical types, and underlying diseases were not significantly different between the two groups (all $P>0.05)$. Notably, there were more patients with chess distress in GC group $(P=0.019)$. In order to rule out the influences of disease progression on prognosis, the time from symptom appearing to hospitalization were analyzed, and it showed no significant difference between the two groups $(P=$ 0.797) (Table 1). 
Table 1

Characteristics of the COVID-19 patients in the GC and control groups

\begin{tabular}{|c|c|c|c|}
\hline Characteristics & $\begin{array}{l}\text { GC group } \\
(n=36)\end{array}$ & $\begin{array}{l}\text { Control } \\
\text { group } \\
(n=30)\end{array}$ & $\mathbf{p}$ \\
\hline \multicolumn{4}{|l|}{ Sex, n (\%) } \\
\hline Male & $\begin{array}{l}14 \\
(38.9 \%)\end{array}$ & $14(46.7 \%)$ & 0.524 \\
\hline Age (years), mean $\pm S D$ & $\begin{array}{l}49.7 \pm \\
16.4\end{array}$ & $49.9 \pm 22.4$ & 0.971 \\
\hline Clinical type, n (\%) & & & 0.463 \\
\hline Regular & $\begin{array}{l}10 \\
(27.8 \%)\end{array}$ & $6(20.0 \%)$ & \\
\hline Severe & $\begin{array}{l}26 \\
(72.2 \%)\end{array}$ & $24(80.0 \%)$ & \\
\hline Smoking history, n (\%) & & & $\overrightarrow{0.999}$ \\
\hline Yes & $2(5.6 \%)$ & $2(6.7 \%)$ & \\
\hline No & $\begin{array}{l}34 \\
(94.4 \%)\end{array}$ & $28(93.3 \%)$ & \\
\hline \multicolumn{4}{|c|}{ Symptoms on hospitalization, $\mathrm{n}(\%)$} \\
\hline Fever & $\begin{array}{l}36 \\
(100 \%)\end{array}$ & $28(93.3 \%)$ & 0.203 \\
\hline Cough & $18(50 \%)$ & $22(73.3 \%)$ & 0.053 \\
\hline Expectoration & $\begin{array}{l}17 \\
(47.2 \%)\end{array}$ & $13(43.3 \%)$ & 0.752 \\
\hline Chest distress & $\begin{array}{l}12 \\
(33.3 \%)\end{array}$ & $2(6.7 \%)$ & 0.019 \\
\hline Chest pain & $1(2.8 \%)$ & $1(3.3 \%)$ & $\begin{array}{l}> \\
0.999\end{array}$ \\
\hline Fatigue & $\begin{array}{l}10 \\
(27.8 \%)\end{array}$ & $12(40.0 \%)$ & 0.294 \\
\hline Sore muscles & $2(5.6 \%)$ & $4(13.3 \%)$ & 0.555 \\
\hline Headache & $1(2.8 \%)$ & $4(13.3 \%)$ & 0.252 \\
\hline
\end{tabular}

GC: glucocorticoids, SD: standard deviation 


\begin{tabular}{|llll|}
\hline Characteristics & $\begin{array}{l}\text { GC group } \\
(\mathbf{n = 3 6})\end{array}$ & $\begin{array}{l}\text { Control } \\
\text { group } \\
(\mathbf{n}=\mathbf{3 0})\end{array}$ & $\mathbf{p}$ \\
\hline Diarrhea & $2(5.6 \%)$ & $1(3.3 \%)$ & $>$ \\
\hline $\begin{array}{l}\text { Time from symptom appearing to hospitalization (Day), median } \\
\text { (range) }\end{array}$ & $2(0-5)$ & $1(0-5)$ & 0.799 \\
\hline GC: glucocorticoids, SD: standard deviation & & & \\
\hline
\end{tabular}

\section{Comparisons of duration of clinical symptoms and 28-d prognoses}

The durations of chest distress and fever were both significantly shorter in the GC group than control group ( $P=0.006, P=0.036)$, while the other symptoms were not significantly different. As shown in Table 2, the median time of hospital stay, and 28-d prognoses were not significantly different between the two groups $(P=0.080, P>0.999)$. One patient in each group died due to disease progression.

Table 2

Comparisons of clinical symptoms and prognoses of COVID-19 patients in the GC and control groups

\begin{tabular}{|c|c|c|c|}
\hline Characteristics & $\begin{array}{l}\mathrm{GC} \\
36)\end{array}$ & $\begin{array}{l}\text { Control group }(n= \\
30)\end{array}$ & $\mathbf{p}$ \\
\hline Duration of fever (Day), median (range) & $6(4-9)$ & $9(6-12)$ & 0.036 \\
\hline \multirow{2}{*}{$\begin{array}{l}\text { Peak body temperature (Celsius), median } \\
\text { (range) }\end{array}$} & 38.4 & 38.3 & \multirow[t]{2}{*}{0.391} \\
\hline & $(37.9-38.8)$ & $(37.9-38.8)$ & \\
\hline $\begin{array}{l}\text { Duration of chest distress (Day), median } \\
\text { (range) }\end{array}$ & $2(1-3)$ & $6(5-7)$ & 0.006 \\
\hline Time of hospital stay (Day), median (range) & $13(12-17)$ & $12(11-15)$ & 0.080 \\
\hline 28-d prognosis, n (\%) & & & $\overrightarrow{0.999}$ \\
\hline Cure & $31(86.1 \%)$ & $26(86.7 \%)$ & \\
\hline Disease progression & $4(11.1 \%)$ & $3(10.0 \%)$ & \\
\hline Death & $1(2.8 \%)$ & $1(3.3 \%)$ & \\
\hline
\end{tabular}

GC: glucocorticoids

\section{Comparisons of immunological parameters}

The examination results were not significantly different between the two groups within $24 \mathrm{~h}$ after hospitalization and on day 14 (all $P>0.05$ ). However, as shown in Fig. $1 \mathrm{~F}$ and $1 \mathrm{~J}$, the CRP and IL-6 levels 
in the GC group were significantly lower than control group at $7 \mathrm{~d}$ after hospitalization $(P=0.012, P=$ 0.035), while the other parameters were not significantly different between the two groups $($ all $P>0.05)$ (Fig. 1).

\section{Changes of inflammatory and immune indicators in GC group}

After glucocorticoids treatment, the CRP and IL-6 levels in GC group decreased after day 3 and continued day 5 and day 7, which were significantly different from the levels before glucocorticoids treatment (all $P$ $<0.05$ ) (Fig. 2). The LYM, NLR, absolute count of CD $4^{+}$T lymphocytes, and absolute count of CD $8^{+} \mathrm{T}$ lymphocytes did not change significantly during the treatment, as well as before and after the treatment (all $P>0.05$ ) (Fig. 2).

\section{Discussion}

COVID-19 has become a major issue in recent months with respect to its treatment and recovery, due to increased mortality rate. No effective clinical protocols and drug regime is currently available in the treatment of COVID-19. In recent months, application of glucocorticoids in treating COVID-19 has been ventured by different hospitals based on their application during SARS [8]. Down-regulation of immune responses induced by cytokine storm and reduction of lymphocytes has been considered as an important mechanism of severe COVID-19 [4]. Our study retrospectively analyzed the data of 66 COVID-19 patients, and found that the more patients were with chest distress in GC group than control group, but the duration of chest distress was shorter. Similarly, fever duration in the GC group was significantly shorter than control group. Also, the CRP and IL-6 levels in the GC group were lower than control group at $7 \mathrm{~d}$ after hospitalization.

Our study demonstrated that GC helped improving the chest distress and fever in the patients. The pathogenic investigations showed that COVID-19 infection activated the innate immunity and adaptive immunity of the system [14], consequently inducing the release of cytokines and aggregation of inflammatory cells, which not only damaged the mucosal-epithelial barrier of airway [15,16], but also could induce diffuse alveolar damages, including apoptosis of alveolar cells, hyaline membrane formation, and pulmonary edema [17]. They not only cause dyspnea, but also secondary infection. So, COVID-19 not only activates the immune responses of patients, but also causes adverse outcomes due to excessive immune responses. However, glucocorticoids could down-regulate these inflammatory responses, which can alleviate clinical symptoms.

To further investigate whether glucocorticoids could influence the immune and inflammatory status of COVID-19 patients, changes in the immune-related indicators and inflammatory factors during the treatment in both groups were compared. The count of lymphocytes and absolute count of CD4 ${ }^{+}$and $\mathrm{CD}^{+} \mathrm{T}$ lymphocytes were significantly lower shortly after hospitalization than before allotting them in both groups, but their differences between the two groups were not statistically significant. So, 
glucocorticoids were not the cause of decreased lymphocytes in the patients. To rule out the influence of hospitalization time on the outcomes, the time from symptom appearing to hospitalization was compared between the two groups, which showed no statistically significant difference. Another study showed that corticosteroid treatment did not influence hospital length of stay, or duration of symptoms in patients with mild COVID-19 [10]. The secretion of cytokines and chemokines after COVID-19 infection, induced the migration of immune cells, mainly include monocytes and lymphocytes, but not neutrophils, to the sites of infection [17]. Some studies reported decreased LYM and increased NLR in about $80 \%$ of COVID-19 patients $[18,19]$. In addition, NLR could be an independent predictor for the severity of COVID-19 [20]. NLR not only reflects the systemic immune status [21], but also associates with the immune function impairment of the system. Our study findings showed that the changes of NLR were not significantly different between the two groups. Also, the 28-d prognoses of patients were also not significantly different between the two groups, suggesting that short-term application of low- to moderate- dose glucocorticoids did not aggravate the disease conditions.

The findings of this study showed that the CRP and IL- 6 levels in the GC group were lower than control group at $7 \mathrm{~d}$ after hospitalization, suggesting the glucocorticoids role in reducing the levels of inflammatory factors. CRP and IL-6 levels of patients treated with low- to moderate- dose glucocorticoids decreased, which reached the lowest levels at $5 \mathrm{~d}$ after hospitalization. To rule out the timing of drug application on the results, the time from hospitalization to the first dosing of glucocorticoids was analyzed, which showed that the median time from hospitalization to the first dosing of glucocorticoids was 3 days, and the median time from symptom appearing to the first dosing of glucocorticoids was 6 days, which were generally in agreement with the time of inflammatory mediator reduction shown in the comparisons between the two groups. These findings suggested that the application of glucocorticoids reduced the levels of inflammatory mediator [22]. However, the inflammatory mediator levels were not significantly different between the two groups on day 14 , suggesting that the inflammatory mediator levels could decrease with the improvement of disease conditions, and glucocorticoids may only accelerate the decrease in a certain degree. More clinical studies are needed to verify and further provide evidence for the standardization of glucocorticoids treatment.

This study was a retrospective study, and there were several limitations in this study. Missing data, relatively small sample size, and no further analysis for the clinical subtypes limited the extrapolation of the findings. Therefore, more clinical trials with rigorous study design is essential to investigate further the timing and doses of glucocorticoids and understand their clinical outcome.

\section{Conclusions}

In summary, low- to moderate- dose glucocorticoids could down-regulate the levels of inflammatory mediators to a certain degree in regular or severe COVID-19 patients. However, glucocorticoids didn't influence the lymphocyte count, $T$ lymphocyte subsets, and 28-d prognosis substantially. The findings suggested that application of low- to moderate- dose glucocorticoids in appropriate time window can be beneficial for patients with regular or severe type COVID-19, which needs further clinical trials. 


\section{Abbreviations}

SARS

severe acute respiratory syndrome; GC:glucocorticoids; CRP:C-reactive protein.

\section{Declarations}

Ethics approval and consent to participate

The authors are accountable for all aspects of the work in ensuring that questions related to the accuracy or integrity of any part of the work are appropriately investigated and resolved. The study was conducted in accordance with the Declaration of Helsinki (as revised in 2013). The study was approved by the ethics committee of Henan Provincial People's Hospital. (2020 ethics review of Num 87) and individual consent for this retrospective analysis was waived.

Consent for publication

Not applicable

Availability of data and materials

The datasets used and/or analysed during the current study are available from the corresponding author on reasonable request.

Competing interests

The authors declare that they have no conflicts of interests.

\section{Funding}

This study was supported by the 2020 Key Emergency Project for the Prevention and Management of COVID-19 (201100310700).

\section{Authors' contributions}

Conception and design: Jing Zhang; Administrative support: Yong Qi, Xiao- Ju Zhang; Provision of study materials or patients: Yi Kang, Hai-Bo Wang; Collection and assembly of data: Hai-Yang Liu, Ya-Nan Qi, Xia Tang; Data analysis and interpretation: Jing Zhang; Manuscript writing: All authors; Final approval of manuscript: All authors

\section{Acknowledgements}

The authors would like to thank all study participants who were enrolled in this study. 


\section{References}

1. Chen N, Zhou M, Dong X, Qu J, Gong F, Han Y, et al. Epidemiological and clinical characteristics of 99 cases of 2019 novel coronavirus pneumonia in wuhan, china: A descriptive study. Lancet. 2020;395(10223):507-13. doi: 10.1016/s0140-6736(20)30211-7.

2. Cao B, Wang Y, Wen D, Liu W, Wang J, Fan G, et al. A trial of lopinavir-ritonavir in adults hospitalized with severe covid-19. N Engl J Med. 2020;382(19):1787-99. doi: 10.1056/NEJMoa2001282.

3. Chan JF, Yuan S, Kok KH, To KK, Chu H, Yang J, et al. A familial cluster of pneumonia associated with the 2019 novel coronavirus indicating person-to-person transmission: A study of a family cluster. Lancet. 2020;395(10223):514-23. doi: 10.1016/s0140-6736(20)30154-9.

4. Huang C, Wang Y, Li X, Ren L, Zhao J, Hu Y, et al. Clinical features of patients infected with 2019 novel coronavirus in wuhan, china. Lancet. 2020;395(10223):497-506. doi: 10.1016/s01406736(20)30183-5.

5. Jin YH, Cai L, Cheng ZS, Cheng H, Deng T, Fan YP, et al. A rapid advice guideline for the diagnosis and treatment of 2019 novel coronavirus (2019-ncov) infected pneumonia (standard version). Mil Med Res. 2020;7(1):4. doi: 10.1186/s40779-020-0233-6.

6. Sibila O, Luna CM, Agustí C, Baquero S, Gando S, Patrón JR, et al. Effects of glucocorticoids in ventilated piglets with severe pneumonia. Eur Respir J. 2008;32(4):1037-46. doi: 10.1183/09031936.00009208.

7. Hui DS. Systemic corticosteroid therapy may delay viral clearance in patients with middle east respiratory syndrome coronavirus infection. Am J Respir Crit Care Med. 2018;197(6):700-01. doi: 10.1164/rccm.201712-2371ED.

8. Auyeung TW, Lee JS, Lai WK, Choi CH, Lee HK, Lee JS, et al. The use of corticosteroid as treatment in sars was associated with adverse outcomes: A retrospective cohort study. J Infect. 2005;51(2):98102. doi: 10.1016/j.jinf.2004.09.008.

9. Haberman R, Axelrad J, Chen A, Castillo R, Yan D, Izmirly P, et al. Covid-19 in immune-mediated inflammatory diseases - case series from new york. N Engl J Med. 2020;383(1):85-88. doi: 10.1056/NEJMc2009567.

10. Zha L, Li S, Pan L, Tefsen B, Li Y, French N, et al. Corticosteroid treatment of patients with coronavirus disease 2019 (covid-19). Med J Aust. 2020;212(9):416-20. doi: 10.5694/mja2.50577.

11. Banerjee D, Popoola J, Shah S, Ster IC, Quan V, Phanish M. Covid-19 infection in kidney transplant recipients. Kidney Int. 2020;97(6):1076-82. doi: 10.1016/j.kint.2020.03.018.

12. Qin YY, Zhou YH, Lu YQ, Sun F, Yang S, Harypursat V, et al. Effectiveness of glucocorticoid therapy in patients with severe coronavirus disease 2019: Protocol of a randomized controlled trial. Chin Med J (Engl). 2020;133(9):1080-86. doi: 10.1097/cm9.0000000000000791.

13. Russell CD, Millar JE, Baillie JK. Clinical evidence does not support corticosteroid treatment for 2019ncov lung injury. Lancet. 2020;395(10223):473-75. doi: 10.1016/s0140-6736(20)30317-2. 
14. Chen R, Sang L, Jiang M, Yang Z, Jia N, Fu W, et al. Longitudinal hematologic and immunologic variations associated with the progression of covid-19 patients in china. J Allergy Clin Immunol. 2020;146(1):89-100. doi: 10.1016/j.jaci.2020.05.003.

15. Saatian B, Rezaee F, Desando S, Emo J, Chapman T, Knowlden S, et al. Interleukin-4 and interleukin13 cause barrier dysfunction in human airway epithelial cells. Tissue Barriers. 2013;1(2):e24333. doi: $10.4161 /$ tisb. 24333 .

16. Wong CK, Lam CW, Wu AK, Ip WK, Lee NL, Chan IH, et al. Plasma inflammatory cytokines and chemokines in severe acute respiratory syndrome. Clin Exp Immunol. 2004;136(1):95-103. doi: 10.1111/j.1365-2249.2004.02415.x.

17. Xu Z, Shi L, Wang Y, Zhang J, Huang L, Zhang C, et al. Pathological findings of covid-19 associated with acute respiratory distress syndrome. Lancet Respir Med. 2020;8(4):420-22. doi: 10.1016/s22132600(20)30076-x.

18. Guan WJ, Ni ZY, Hu Y, Liang WH, Ou CQ, He JX, et al. Clinical characteristics of coronavirus disease 2019 in china. N Engl J Med. 2020;382(18):1708-20. doi: 10.1056/NEJMoa2002032.

19. Qin C, Zhou L, Hu Z, Zhang S, Yang S, Tao Y, et al. Dysregulation of immune response in patients with coronavirus 2019 (covid-19) in wuhan, china. Clin Infect Dis. 2020;71(15):762-68. doi: $10.1093 / \mathrm{cid} / \mathrm{ciaa} 248$.

20. Liu J, Liu Y, Xiang P, Pu L, Xiong H, Li C, et al. Neutrophil-to-lymphocyte ratio predicts critical illness patients with 2019 coronavirus disease in the early stage. J Transl Med. 2020;18(1):206. doi: 10.1186/s12967-020-02374-0.

21. Kolber W, Kuśnierz-Cabala B, Maraj M, Kielar M, Mazur P, Maziarz B, et al. Neutrophil to lymphocyte ratio at the early phase of acute pancreatitis correlates with serum urokinase-type plasminogen activator receptor and interleukin 6 and predicts organ failure. Folia Med Cracov. 2018;58(4):57-74.

22. Zhang W, Zhao Y, Zhang F, Wang Q, Li T, Liu Z, et al. The use of anti-inflammatory drugs in the treatment of people with severe coronavirus disease 2019 (covid-19): The perspectives of clinical immunologists from china. Clin Immunol. 2020;214:108393. doi: 10.1016/j.clim.2020.108393.

\section{Figures}



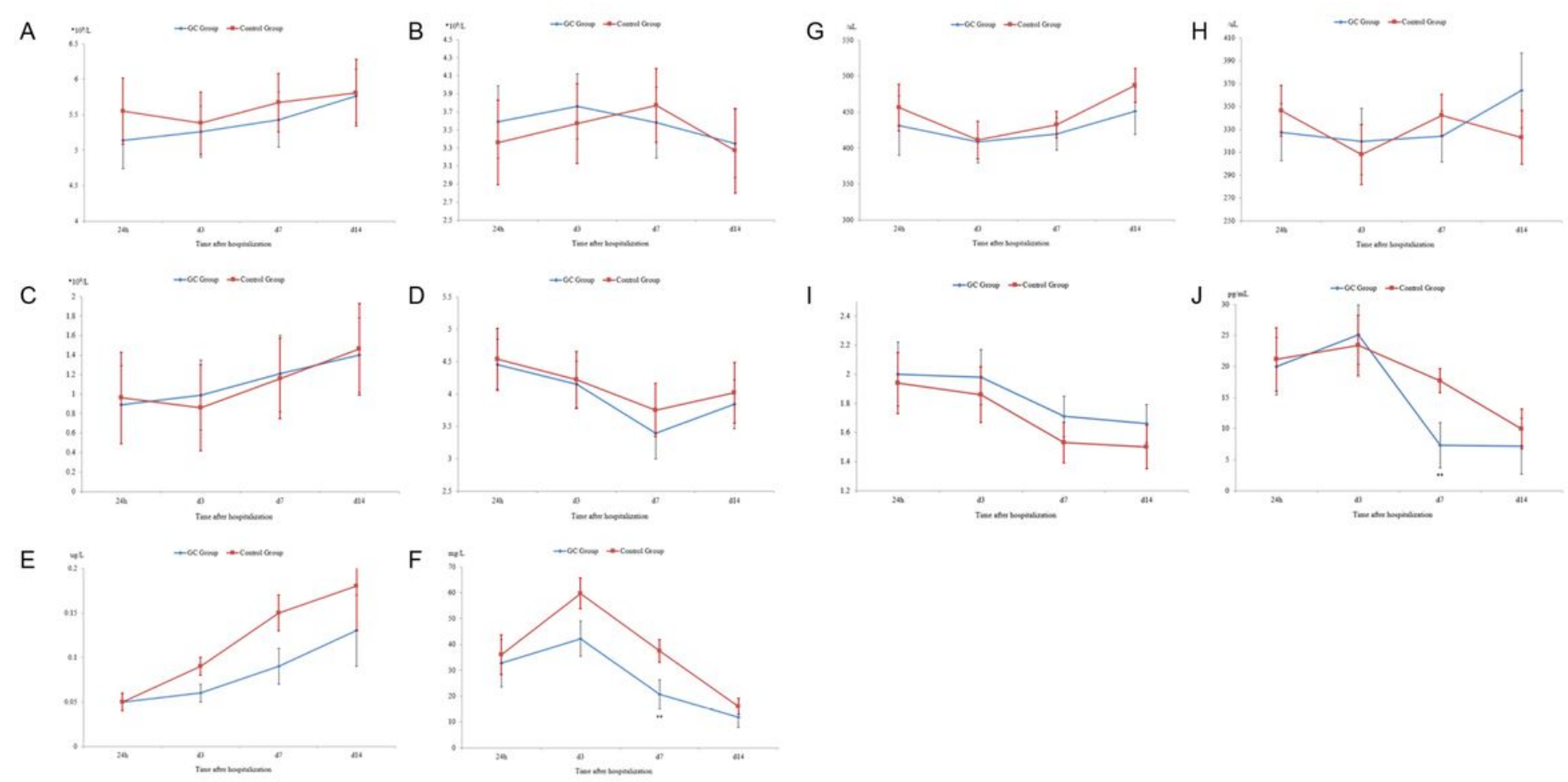

\section{Figure 1}

Comparisons of examination results of the COVID-19 patients in the glucocorticoids (GC) and control groups: A: white blood cell; B: neutrophil cell (NEU); C: lymphocyte (LYM); D: NEU/LYM; E: procalcitonin; F: C-reactive protein(CRP); G: CD4+ cell; H: CD8+ cell; I: CD4+/CD8+; J: Interleukin-6. ** represented the pvalue of the comparison between two groups was $<0.05$.

A :

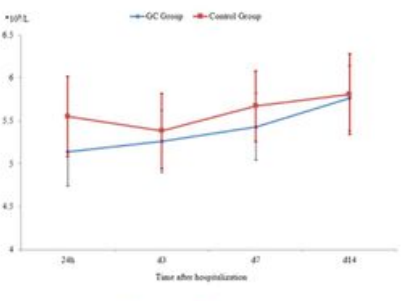

c

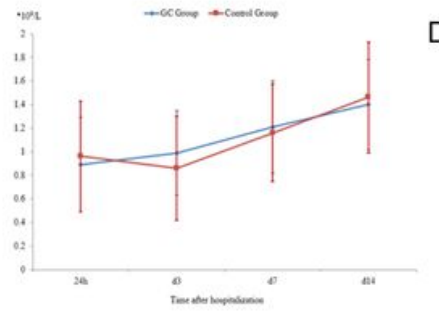

$\mathrm{E}$

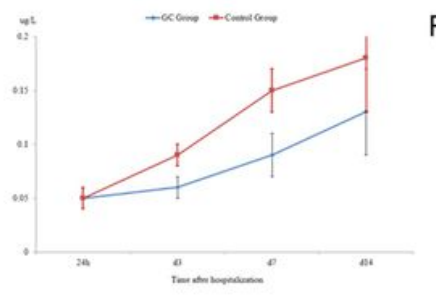

B

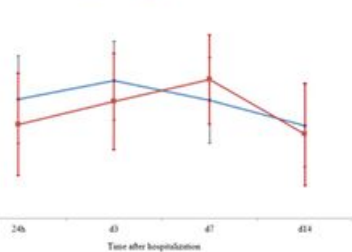

$\mathrm{D}$

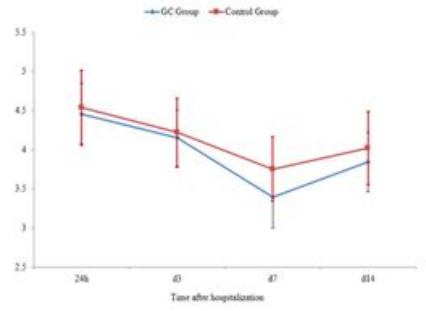

$\mathrm{F}$

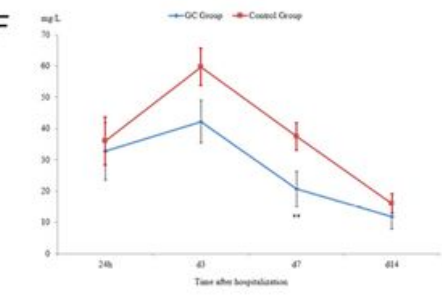

$G$

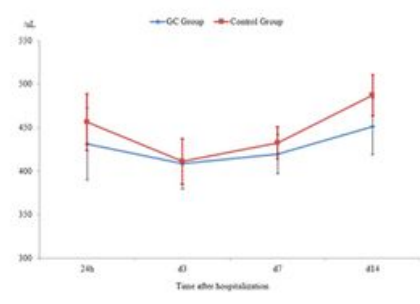

I

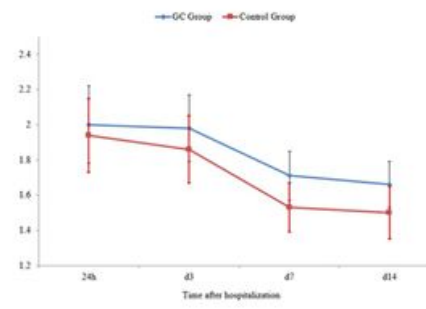

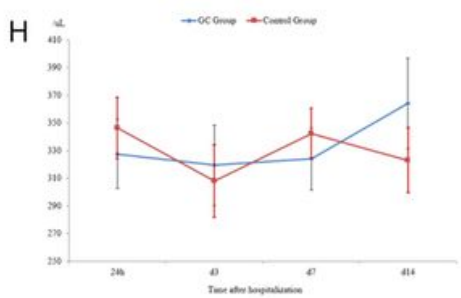

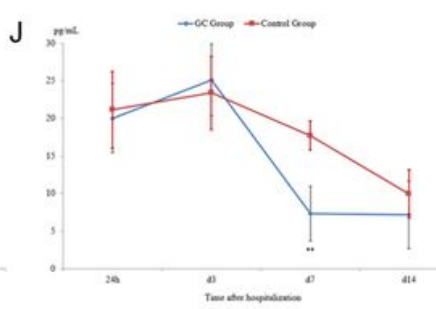

\section{Figure 1}


Comparisons of examination results of the COVID-19 patients in the glucocorticoids (GC) and control groups: A: white blood cell; B: neutrophil cell (NEU); C: lymphocyte (LYM); D: NEU/LYM; E: procalcitonin; F: C-reactive protein(CRP); G: CD4+ cell; H: CD8+ cell; I: CD4+/CD8+; J: Interleukin-6. ** represented the pvalue of the comparison between two groups was $<0.05$.
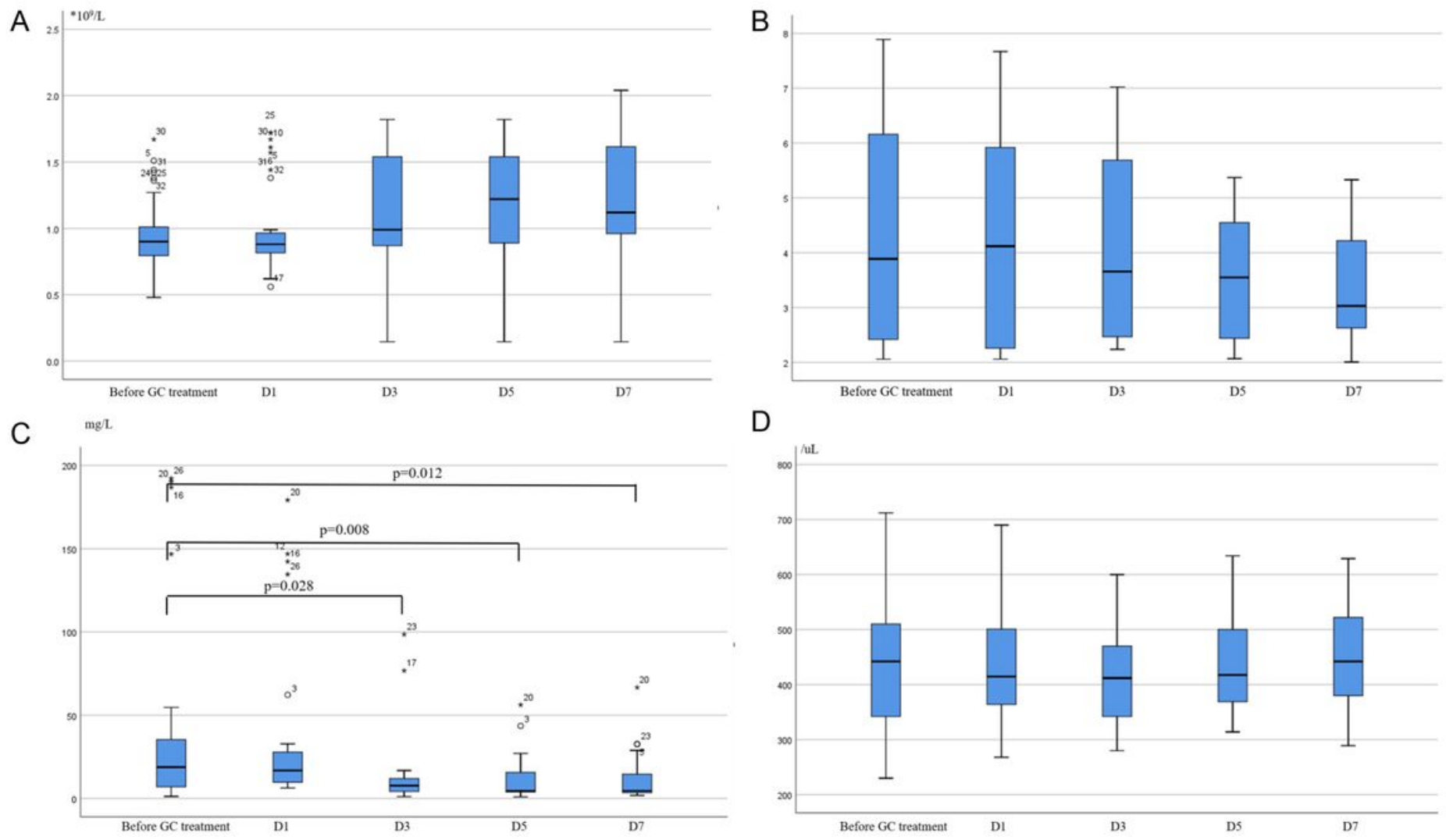

D
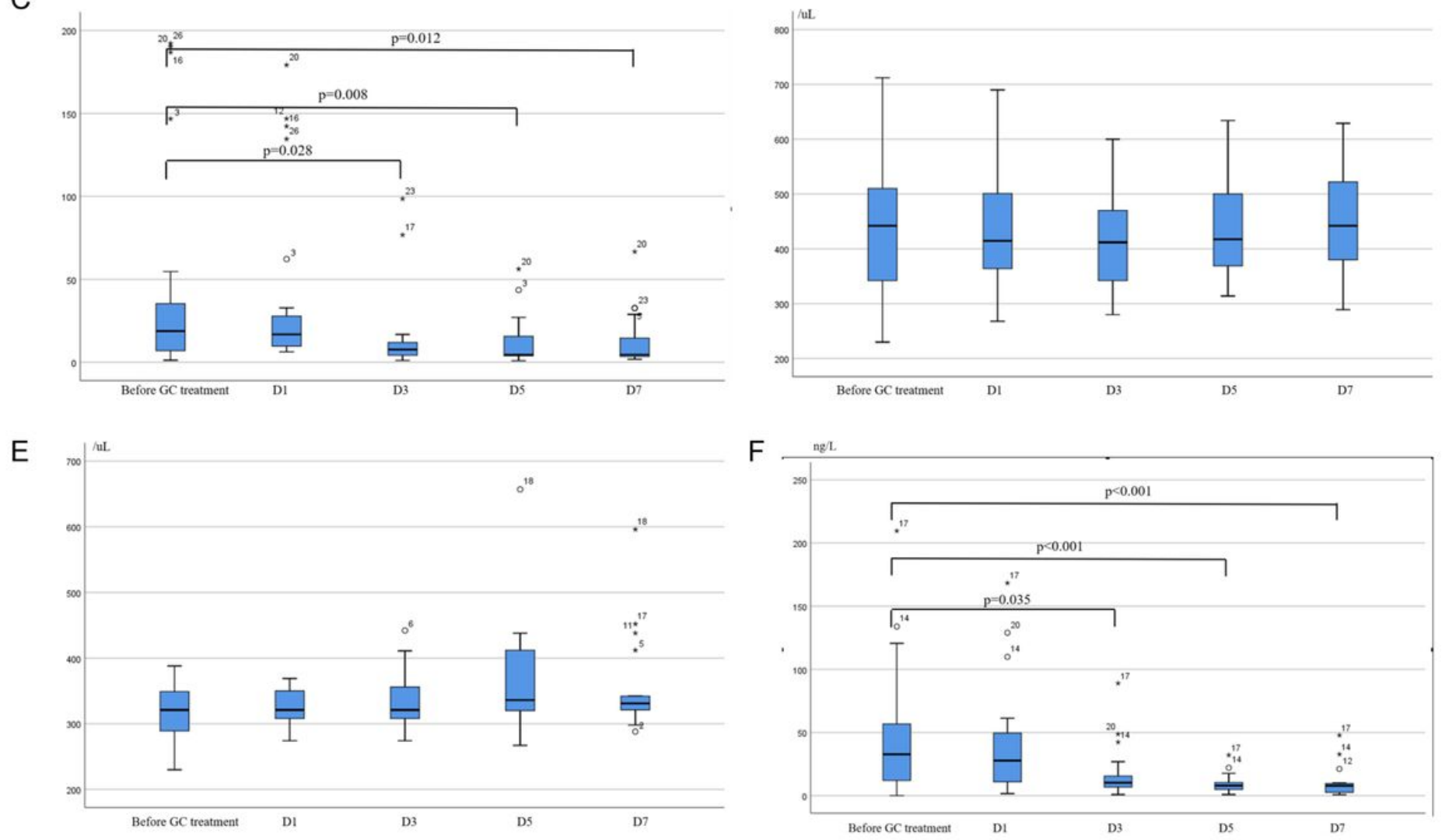

\section{Figure 2}

Comparisons of inflammatory and immune indicators before and after treatment in the glucocorticoids (GC) group: A: lymphocyte (LYM); B: neutrophil cell/LYM; C: C-reactive protein (CRP); D: CD4+ cell; E: CD8+ cell; F: IL-6. 
$A_{2}$

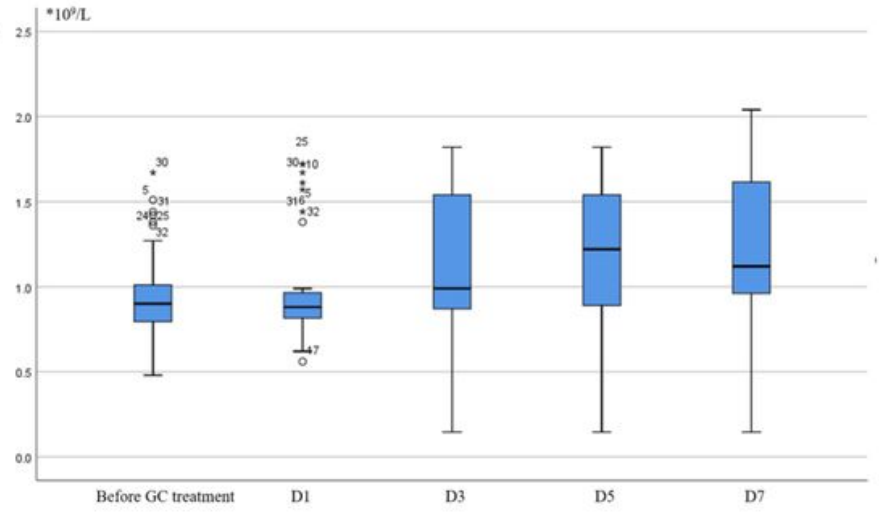

C

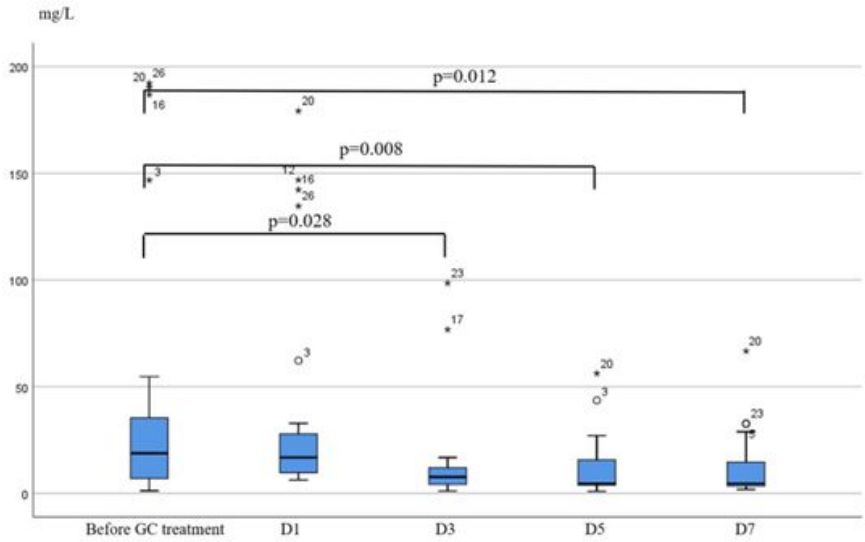

E

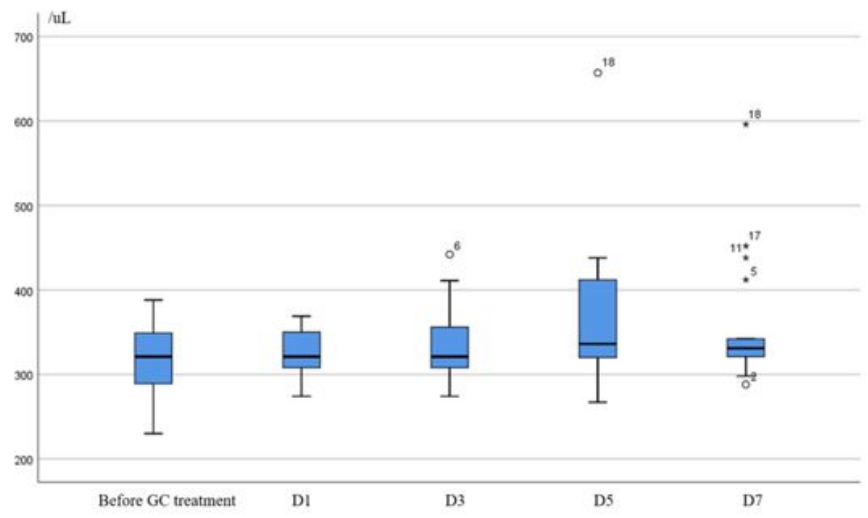

B

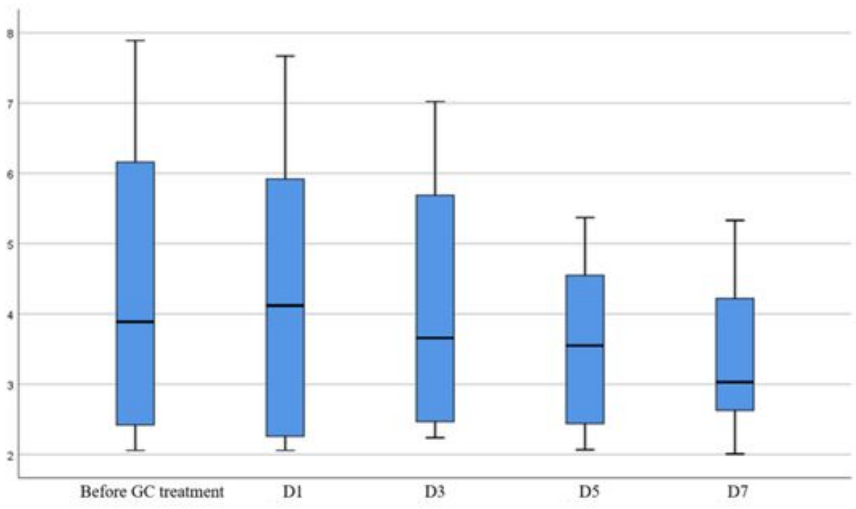

D

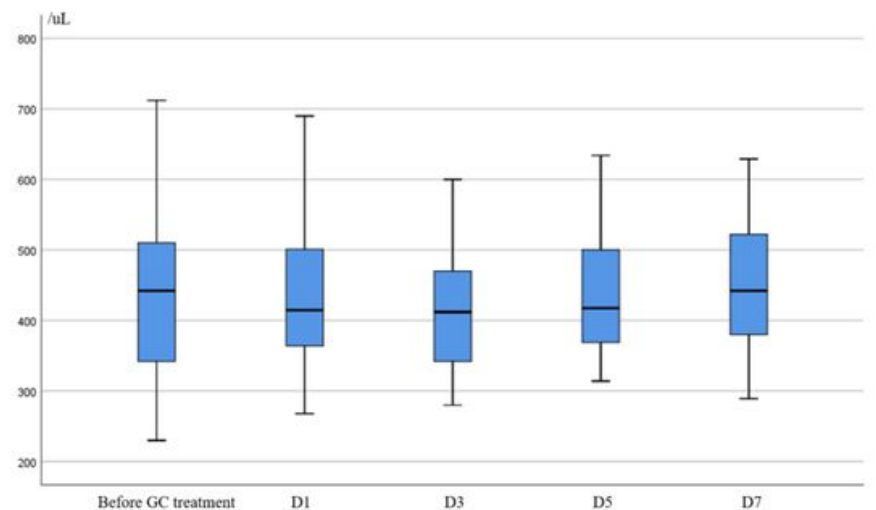

F

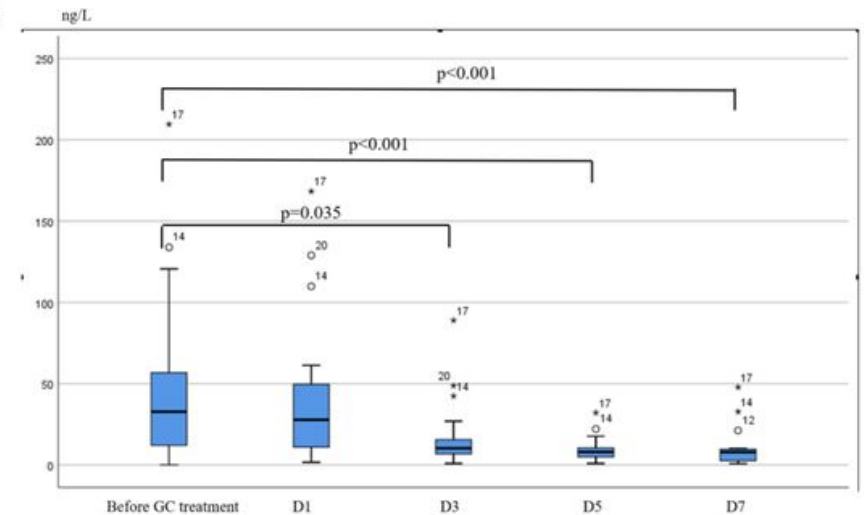

Figure 2

Comparisons of inflammatory and immune indicators before and after treatment in the glucocorticoids (GC) group: A: Iymphocyte (LYM); B: neutrophil cell/LYM; C: C-reactive protein (CRP); D: CD4+ cell; E: CD8+ cell; F: IL-6. 